\title{
IMPLEMENTASI ALGORITMA MODIFIED GUSTAFSON-KESSEL UNTUK CLUSTERING TWEETS PADA AKUN TWITTER LAZADA INDONESIA
}

\author{
Ratna Kencana Putri ${ }^{1}$, Budi Warsito ${ }^{2}$, Mustafid ${ }^{3}$ \\ 1,2,3 Departemen Statistika FSM Universitas Diponegoro \\ budiwrst2@gmail.com
}

\begin{abstract}
Online social media is a new kind of media which is steadily growing and has become publicly popular. Due to its ability to spread informations rapidly and its easiness to access for internet users, social media provides new alternative to conduct advertising and product segmentation. Twitter is one of the most favored social media with 19.5 million users in Indonesia to the date. In this research, the application of text mining to cluster tweets from the @LazadaID Twitter account is done using the Modified Gustafson-Kessel clustering algorithm. The clustering process is executed five times with the number of cluster starts from two to six cluster. The results of this research indicate that the optimum number of clusters formed based on the Partition Coefficient and Classification Entropy validation index are three clusters. Those three clusters are tweets containing electronic stuff offers, discounts, and prize quizes. Tweets with the most retweets and likes are prize quiz tweets. PT Lazada Indonesia could use this kind of tweet to conduct advertising on social media Twitter because the prize quiz tweets are liked by the @ LazadaID Twitter account followers.
\end{abstract}

Keywords: Twitter, advertising, Lazada Indonesia, Gustafson-Kessel Clustering algorithm, validation index.

\section{PENDAHULUAN}

Pada era digital ini, berbagai macam teknologi komunikasi hadir di kehidupan manusia untuk memperoleh informasi. Perkembangan internet sebagai media baru (the second media age) menandai periode baru dimana teknologi interaktif dan komunikasi jaringan khususnya dunia maya akan mengubah masyarakat [8]. Internet memberikan kemudahan bagi para penggunanya untuk mengakses informasi dengan sistem online yang dapat diakses kapanpun dan dimanapun. Media sosial online telah menjadi suatu media baru yang semakin berkembang dan populer di lingkungan masyarakat dan secara umum digunakan untuk mengekspresikan diri dan menyampaikan pendapat pengguna terhadap segala hal secara bebas.

Twitter merupakan salah satu media sosial yang paling populer di Indonesia dengan 19,5 juta pengguna di Indonesia dari total 500 juta pengguna global [10]. Setiap pengguna Twitter dapat dengan bebas membuat tweets dengan kalimat apapun yang menggambarkan kehidupan, pendapat, ataupun kejadian tertentu. Dengan fasilitas tersebut maka banyak perusahaan yang akhirnya menggunakan Twitter sebagai alat advertising serta media untuk menyebarkan informasi. Salah satu perusahaan yang menggunakan Twitter sebagai alat promosi adalah PT Lazada Indonesia dengan nama akun twitter @LazadaID.

PT Lazada Indonesia menduduki peringkat pertama e-commerce paling top di Indonesia dengan jumlah kunjungan ke laman lebih dari 117 juta visit, 364 ribu pengikut di Twitter, 1 juta pengikut di Instagram, dan 22,7 juta pengikut di Facebook [1]. Lazada menggunakan akun Twitter tersebut untuk memberikan informasi mengenai produk-produk yang dijual, promo yang sedang ditawarkan, serta penawaran-penawaran lain untuk menarik 
minat pembeli agar melakukan transaksi di Lazada. Pelaku bisnis harus mampu memahami jenis konten yang mendapat respon positif dari followers, agar dapat menentukan strategi pemasaran yang tepat.

Metode text mining dapat digunakan untuk menganalisa data pada Twitter karena sebagian besar informasi yang tersedia dalam Twitter disimpan dalam bentuk data teks [6]. Salah satu tahapan lanjutan dari metode text mining yaitu clustering untuk menentukan pola dan struktur yang menarik dari sebuah data yang berjumlah sangat besar dengan latar belakang pengetahuan yang sedikit [13]. Metode clustering yang saat proses pengelompokannya fleksibel mengikuti bentuk data adalah Algoritma Gustafson-Kessel. Dalam analisis cluster memerlukan suatu indeks untuk mengetahui banyaknya cluster optimum yang cocok pada suatu penelitian [9]. Salah satu, indeks validitas yang cocok untuk fuzzy clustering adalah indeks validitas Partition Coefficient (PC) dan Classification Entropy (CE).

Dalam penelitian ini akan dilakukan pengelompokan tweets dari akun Twitter @LazadaID menggunakan algoritma Modified Gustafson-Kessel clustering. Penelitian akan menggunakan tweets yang diunggah akun Twitter @LazadaID serta jumlah retweet dari masing-masing tweets yang diunggah untuk mengetahui tweets yang paling disukai oleh para pengikut (followers) akun @LazadaID yang akan diolah menggunakan perangkat lunak RStudio dan MatLab R2015a.

\section{TINJAUAN PUSTAKA}

\subsection{Pemasaran Media Sosial}

Pemasaran media sosial adalah segala bentuk pemasaran langsung atau tidak langsung yang digunakan untuk membangun kesadaran, pengenalan, pengingatan kembali, dan pengambilan aksi terhadap sebuah merek, bisnis, produk, orang, atau hal lainnya yang dikemas menggunakan alat-alat di social web, seperti blogging, microblogging, social networking, social bookmarking, dan content sharing [7]. Banyak perusahaan yang menerapkan pemasaran media sosial dengan pertimbangan biaya (cost) yang cukup rendah namun memiliki pengaruh yang cukup tinggi dalam mendapatkan konsumen. Perusahaan yang menggunakan metode ini biasanya merupakan perusahaan yang bergerak di bidang $e$ commerce.

Sebelum menentukan strategi pemasaran, perusahaan harus mengetahui faktor yang mempengaruhi perilaku konsumen. Salah satu faktor yang memengaruhi perilaku pembelian online konsumen adalah persepsi manfaat. Pencarian online dan persepsi manfaat akan memberikan efek positif terhadap frekuensi belanja online [5]. Faktor lain yang memengaruhi adalah persepsi risiko. Persepsi risiko konsumen akan meningkat melalui dan atau besarnya hubungan konsekuensi yang negative [12]. Opini yang tersebar melalui komunitas internet juga akan mempengaruhi proses keputusan pembelian online. Sebelum pembeli memutuskan untuk melakukan pembelian barang pastinya pembeli akan mencari referensi dari orang lain sebagai bahan pertimbangan.

\subsection{Text Mining}

Text Mining dapat didefinisikan secara luas sebagai suatu proses menggali informasi yang berasal dari sekumpulan dokumen dari waktu ke waktu menggunakan serangkaian alat analisis untuk mengidentifikasi dan mengeksplorasi pola data yang ada [6]. Pada dasarnya text mining memiliki konsep pengolahan yang hampir sama dengan data mining, perbedaannya yaitu terdapat pada sumber data yang digunakan. Sumber data text mining berupa teks tidak terstruktur, sedangkan data mining menggunakan data terstruktur. 
Sehingga text mining merupakan sebuah penemuan baru dari informasi yang belum diketahui dengan mengekstrak informasi dari sumber tertulis. Tahap-tahap text mining adalah sebagai berikut [6]:

a. Text Preprocessing

Text preprocessing meliputi berbagai jenis teknik ekstraksi informasi yang mengubah format mentah, tidak terstruktur, dan memiliki format asli menjadi terstruktur dan dapat diolah pada tahapan berikutnya [6]. Tahap-tahap preprocessing yang dilakukan antara lain:

- Case Folding, yaitu mengkonversi keseluruhan karakter huruf dalam dokumen menjadi huruf kecil.

- Remove URL, yaitu menghilangkan link internet (URL).

- Remove mention, yaitu menghilangkan rujukan kepada pengguna akun Twitter lain.

- Unescape HTML, yaitu menghilangkan bahasa markah yang berupa kode-kode tag.

- Remove Number, Remove Punctuation, dan Remove Emoticon, yaitu menghilangkan karakter selain huruf alphabet yang berupa angka dan tanda baca.

- Menerjemahkan kalimat dengan bahasa berbeda menjadi satu bahasa yang sama.

- StripWhiteSpace, yaitu menghapus spasi yang berlebih pada dokumen.

- Tokenizing, yaitu memecah sekumpulan karakter dalam suatu teks ke dalam satuan kata.

b. Feature Selection

Feature Selection merupakan tahapan untuk mengurangi dimensi dari sebuah data tekstual dengan menghapus kata-kata yang tidak relevan sehingga proses pengelompokan lebih efektif dan akurat [6]. Proses yang dilakukan pada tahapan ini adalah:

- Stopword Removal, yaitu menghapus kata-kata yang sering muncul dalam suatu dokumen, namun memiliki arti yang tidak deskriptif dan dapat dibuang. Data stopwords dapat diambil dari thesis Fadillah Z Tala yang berjudul "A Study of Stemming Effects on Information Retrieval in Bahasa Indonesia".

- Stemming, yaitu proses mengubah berbagai kata berimbuhan menjadi kata dasarnya [15]. Algoritma stemming yang digunakan adalah algoritma stemming Pujangga.

c. Text Representation

Text representation merupakan tahapan mengubah data tekstual menjadi representasi yang lebih mudah untuk diproses. Salah satu pendekatan untuk text representation ini adalah dengan menggunakan matriks dokumen atau yang biasa disebut Document Term Matrix. Baris pada matriks mewakili dokumen yang digunakan, sedangkan kolom pada matriks berisi kata-kata, frase atau unit hasil indexing lainnya dalam suatu dokumen yang digunakan untuk mengetahui konteks dari dokumen tersebut (terms).

Untuk mempermudah tahap representasi teks dapat digunakan wordcloud untuk mengidentifikasi kata-kata yang ada pada data dokumen. Word cloud adalah presentasi grafis dari suatu dokumen, biasanya dihasilkan dengan memetakan kata-kata paling umum dari suatu dokumen dalam dua dimensi ruang, dengan frekuensi kata yang ditunjukkan oleh ukuran hurufnya [3].

Setiap kata memiliki tingkat kepentingan yang berbeda dalam dokumen, sehingga perlu dilakukan pembobotan untuk setiap kata yang digunakan. TF-IDF merupakan suatu cara untuk memberikan bobot hubungan suatu kata atau term terhadap suatu dokumen [13]. TF-IDF dihitung menggunakan sebagai berikut [6]: 


$$
W_{j, i}=\frac{n_{j, i}}{\sum_{j=1}^{p} n_{j, i}} \cdot \log _{2} \frac{D}{d_{i}}
$$

dengan:

$W_{\mathrm{j}, \mathrm{i}} \quad=$ pembobotan TF-IDF untuk term ke-j pada dokumen ke-i.

$n_{j, i} \quad=$ jumlah kemunculan term ke-j pada dokumen ke-i.

$\mathrm{p} \quad=$ banyaknya term yang terbentuk

$\sum_{j=1}^{p} n_{j, i}=$ jumlah kemunculan seluruh term pada dokumen ke-i.

$\mathrm{D} \quad=$ banyaknya dokumen yang dibangkitkan.

$d_{j} \quad=$ banyaknya dokumen yang mengandung term $\mathrm{ke} \mathrm{j}$.

\subsection{Algoritma Modified Gustafson-Kessel Clustering}

Algoritma Gustafson-Kessel mengubah fungsi perhitungan jarak menjadi fungsi jarak adaptif (adaptive distance norm) yang selalu diperbaharui pada setiap iterasi dengan menggunakan matriks fuzzy covariance [8]. Algoritma Gustafson-Kessel menggunakan fungsi jarak mahalanobis sehingga lebih dapat menyesuaikan bentuk geometris untuk sebuah himpunan data, tidak seperti Fuzzy C-Means yang mengasumsikan bahwa bentuk geometris suatu cluster adalah bulat sempurna. Meskipun Gustafson-Kessel lebih unggul dari algoritma $F$ uzzy $C$-Means, masih terdapat masalah saat matriks fuzzy covariance dari data merupakan matriks singular maka perhitungan matriks $\boldsymbol{A}_{k}$ tidak dapat diterapkan [2].

Algoritma Modified Gustafson-Kessel Clustering secara lengkap adalah sebagai berikut [2]: Input data yang akan dikelompokkan sebagai $X$ (matriks $n \times p$ ), tentukan jumlah cluster yang akan dibentuk $(c \geq 2)$, weighting exponent $(m>1)$, maksimum iterasi $\left(t_{\text {max }}\right)$, error terkecil yang diharapkan $(\varepsilon)$, nilai threshold $(\beta)$, dan parameter pembobot $\gamma \in[0,1]$. Bangkitkan bilangan random $u_{i k}, 1 \leq i \leq n ; 1 \leq k \leq c$ sebagai elemen-elemen matriks partisi awal $\boldsymbol{U}_{0}$ dan hitung matriks kovarian $\boldsymbol{F}_{0}$ dari keseluruhan data.

Ulangi untuk $t=1,2, \ldots, t_{\max }$

$$
\sum_{k=1}^{c} u_{i k}^{m}=1,1 \leq i \leq n ; 1 \leq k \leq c
$$

Step 1: Menghitung pusat cluster ke-k $\left(\boldsymbol{v}_{k}\right)$ dengan rumus:

dengan:

$$
\boldsymbol{v}_{k}^{(t)}=\frac{\sum_{i=1}^{n}\left(u_{i k}^{(t-1)}\right)^{m} \boldsymbol{x}_{i}}{\sum_{i=1}^{n}\left(u_{i k}^{(t-1)}\right)^{m}}, 1 \leq k \leq c
$$

$u_{i k}=$ derajat keanggotaan data ke-i pada cluster ke-k.

$m$ = pangkat pembobot untuk fungsi keanggotaan fuzzy

$t \quad=$ banyaknya iterasi

$n \quad$ = banyaknya data

$c \quad=$ banyaknya cluster

Step 2: Menghitung matriks kovarian cluster dengan rumus:

dengan:

$$
\boldsymbol{F}_{\boldsymbol{k}}=\frac{\sum_{i=1}^{n}\left(u_{i k}^{(t-1)}\right)^{m}\left(\boldsymbol{x}_{i}-\boldsymbol{v}_{k}^{(t)}\right)\left(\boldsymbol{x}_{i}-\boldsymbol{v}_{k}^{(t)}\right)^{T}}{\sum_{i=1}^{n}\left(u_{i k}^{(t-1)}\right)^{m}}, 1 \leq k \leq c
$$

$\boldsymbol{x}_{\boldsymbol{i}} \quad=$ vektor data ke-i

$\boldsymbol{v}_{k} \quad=$ pusat cluster $\mathrm{ke}-\mathrm{k}$.

$u_{i k}=$ derajat keanggotaan data ke-i pada cluster ke-k. 


$$
\begin{array}{ll}
m & =\text { pangkat pembobot untuk fungsi keanggotaan fuzzy } \\
t & =\text { banyaknya iterasi } \\
n & =\text { banyaknya data } \\
c & =\text { banyaknya } \text { cluster }
\end{array}
$$

Ekstraksi nilai eigenvectors $\boldsymbol{\phi}$ dan eigenvalues $\lambda$ dari $\boldsymbol{F}_{k}^{\text {new }}$ yang sudah dihitung dengan persamaan:

$$
\boldsymbol{F}_{k}^{\text {new }}=(1-\gamma) \boldsymbol{F}_{k}+\gamma \operatorname{det}\left(\boldsymbol{F}_{0}\right)^{1 / p} \mathbf{I}
$$

dengan:

$\gamma=$ parameter untuk mengatur bentuk matriks fuzzy covariance, $\gamma \in[0,1]$

$\boldsymbol{F}_{\mathbf{0}}=$ matriks kovarian dari seluruh data

$\boldsymbol{F}_{\boldsymbol{k}} \quad=$ matriks fuzzy covariance cluster $\mathrm{ke}-\mathrm{k}$ (pada persamaan 4)

$p \quad=$ banyaknya variabel

$\boldsymbol{I}=$ matriks identitas

Jika rasio antara nilai eigen maksimal dan minimal melewati nilai threshold yang ditentukan, maka rekonstruksi $\boldsymbol{F}_{\boldsymbol{k}}$ dengan penjabaran sebagai berikut:

dengan:

$$
\boldsymbol{F}_{\boldsymbol{k}}=\boldsymbol{\phi} \boldsymbol{\Lambda} \boldsymbol{\phi}^{-1}
$$

$\boldsymbol{\phi}=$ vektor eigen dari matriks fuzzy covariance cluster ke-k

$\boldsymbol{\Lambda}=$ matriks diagonal dari nilai-nilai eigen (eigenvalues) matriks fuzzy covariance cluster ke-k

Step 3: Menghitung jarak dengan persamaan menggunakan persaman sebagai berikut dengan $i=1,2, \ldots, n$ dan $=1,2, \ldots, c$ :

$$
D_{i k A_{k}}^{2}=\left(\boldsymbol{x}_{i}-\boldsymbol{v}_{k}^{(t)}\right)^{T}\left[\rho_{k} \operatorname{det}\left(\boldsymbol{F}_{k}\right)^{1 / p} \boldsymbol{F}_{k}^{-1}\right]\left(\boldsymbol{x}_{i}-\boldsymbol{v}_{k}^{(t)}\right)
$$

dengan:

$D_{i k A_{k}}^{2}=$ jarak data ke-i terhadap pusat cluster ke-k dengan norm inducing matrix $\boldsymbol{A}_{k}$

$\boldsymbol{x}_{\boldsymbol{i}} \quad=$ vektor data ke-i

$\boldsymbol{v}_{k} \quad=$ pusat cluster $\mathrm{ke}-\mathrm{k}$.

$\boldsymbol{F}_{k} \quad=$ matriks fuzzy covarian cluster ke-k.

$\rho_{k} \quad=$ volume cluster ke-k

$p \quad=$ banyaknya variabel

$n \quad=$ banyaknya data

c = banyaknya cluster

Step 4: Memperbaharui matriks fungsi keanggotaan

Untuk $1 \leq i \leq n$

Jika $D_{i k A_{k}}^{2}>0$ untuk $1 \leq k \leq c$

$$
u_{i k}^{(t)}=\left[\sum_{l=1}^{c}\left(\frac{D_{i k A_{k}}}{D_{i l A_{k}}}\right)^{\frac{2}{(m-1)}}\right]^{-1}
$$

Jika tidak, maka:

$$
\begin{aligned}
u_{i k}^{(t)}= & 0 \text { jika } D_{i k A_{k}}^{2}>0 \text { dan } u_{i k}^{(t)} \epsilon[0,1] \\
& \text { dengan } \sum_{k=1}^{c} u_{i k}^{(t)}=1
\end{aligned}
$$

Sampai $\left\|\boldsymbol{U}^{(t)}-\boldsymbol{U}^{(t-1)}\right\|<\varepsilon$ atau jika $t>$ iterasi maksimum

Nilai threshold $(\beta)$ yang digunakan biasanya akan ditentukan dalam angka yang besar, seperti $10^{15}$. Penentuan nilai parameter pembobot $\gamma$ tergantung kepada 
data yang digunakan, beberapa percobaan mungkin perlu dilakukan untuk menentukan nilai $\gamma$ yang tepat.

\subsection{Indeks Validitas Partition Coefficient dan Classification Entropy}

Validasi cluster mengacu kepada masalah apakah partisi yang dibentuk sudah tepat dan bagaimana mengukur ketepatan partisi. Indeks Partition Coefficient mengukur jumlah overlapping antar kelompok. Jumlah cluster optimal ditunjukkan oleh nilai Partition Coefficient yang paling besar [9]. Indeks ini didefiniskan sebagai berikut:

dengan:

$$
P C(c)=\frac{1}{n} \sum_{k=1}^{c} \sum_{i=1}^{n}\left(u_{i k}\right)^{2}
$$

$c$ = banyaknya cluster yang dibuat.

$n$ = banyaknya data yang dikelompokkan.

$u_{i k}=$ derajat keanggotaan data ke-i pada cluster ke-k.

Indeks Classification Entropy (CE) digunakan untuk mengukur kekaburan (fuzziness) dari partisi cluster. Indeks ini memiliki rentang antara 0 sampai dengan $\ln (c)$. Indeks CE yang semakin kecil menunjukkan pengelompokan yang lebih baik. Indeks ini didefinisikan sebagai berikut:

dengan:

$$
C E(c)=\frac{1}{n} \sum_{k=1}^{c} \sum_{i=1}^{n} u_{i k} \ln \left(u_{i k}\right)
$$

$c$ = banyaknya cluster yang dibuat.

$n$ = banyaknya data yang dikelompokkan.

$u_{i k}=$ derajat keanggotaan data ke-i pada cluster ke-k.

\section{METODOLOGI PENELITIAN}

Pengambilan data dilakukan dengan cara crawling data di Twitter berupa data tweet, jumlah retweet, jumlah like, dan tanggal unggahan dengan bantuan Twitter API (Application Programming Interface). Data teks yang digunakan dalam penelitian ini adalah tweets dengan bahasa Indonesia dari beranda akun Twitter @ LazadaID yang bukan termasuk tweet balasan kepada pengguna lain. Tweets yang digunakan merupakan tweets yang diunggah sebelum tanggal 2 Mei 2019 dengan jumlah tweets maksimal yang dapat diambil dari akun Twitter@LazadaID sebanyak 1303 tweets.

Analisis pengelompokan tweets dilakukan menggunakan metode text mining dengan metode lanjutan berupa Algoritma Modified Gustafson-Kessel. Data penelitian diproses menggunakan perangkat lunak RStudio dan MatLab R2015a. Perangkat lunak RStudio digunakan dalam proses crawling data hingga terbentuk document term matrix. Sedangkan perangkat lunak MatLab R2015a digunakan untuk proses clustering data. Setelah didapatkan cluster tweets berdasarkan konten selanjutnya dilakukan profiling masing masing cluster dengan bantuan wordcloud.

\section{HASIL DAN PEMBAHASAN}

Akun Twitter @LazadaID pertama kali diluncurkan pada bulan Maret 2012 dengan jumlah tweets sebanyak 127 ribu tweet serta jumlah pengikut sebanyak 366 ribu akun per Mei 2019, menjadikan akun Twitter @LazadaID sebagai perusahaan e-commerce dengan jumlah pengikut terbanyak di Indonesia.

Pada saat bergabung dengan Twitter API untuk proses crawling data, akan didapatkan beberapa kode berupa consumer key, consumer secret, access token, dan access key yang digunakan sebagai hak akses stream untuk mengambil data text Twitter dengan 
software R. Pengambilan data dilakukan menggunakan fungsi 'tweets $<-$ userTimeline ('LazadaID', n=3200, excludeReplies = TRUE)'.

Tabel 1. Contoh Tweet dari Beranda Twitter @ LazadaID

\begin{tabular}{ccccc}
\hline \multirow{2}{*}{ No } & Text & Tanggal & Jumlah & Jumlah \\
& Tweet & Retweet & Like \\
\hline \multirow{2}{*}{1} & Hi Lazadians! Jangan lupa rawat kulitmu agar & $5 / 2 / 2019$ & & \\
& nutrisinya terpenuhi ya! Cek disini \&gt;\&gt; & \multirow{2}{*}{0} & 2 \\
& https://t.co/iTDVmxB8hO & $7: 34 \mathrm{AM}$ & & \\
\multirow{2}{*}{2} & Ada penawaran menarik nih dari @ Xiaomi! & $5 / 2 / 2019$ & \multirow{2}{*}{0} & \multirow{2}{*}{4} \\
\hline
\end{tabular}

\subsection{Pengolahan Data Teks Menjadi Document Term Matrix}

Data teks diolah melalui tahapan text pre-procesing, feature selection, dan text representation untuk merubah bentuk teks menjadi suatu matriks angka yang digunakan saat proses clustering.

\section{a. Text Preprocessing}

Text preprocessing mengubah format seluruh tweets menjadi suatu data tekstual yang memiliki format sama. Pada tahap ini link internet, mention, HTML, kata yang diawali dengan "laz", dan karakter selain huruf alphabet yang ada pada seluruh tweets akan dihapus. Selanjutnya, karena ada beberapa tweets yang menggunakan bahasa Inggris, maka perlu dilakukan proses menerjemahkan kata ke dalam bahasa Indonesia.

Tabel 2. Contoh Hasil Proses Text Preprocessing

\begin{tabular}{cc}
\hline No. Tweets & Tweets Hasil Text Preprocessing \\
\hline 1 & hi jangan lupa rawat kulitmu agar nutrisinya terpenuhi ya cek disini \\
2 & ada penawaran menarik nih dari xiaomi yakin mau yuk cek \\
sekarang
\end{tabular}

\section{b. Feature Selection}

Feature selection terdiri dari 2 proses yaitu stopword removal dan stemming. Pada proses stopword removal, penghapusan kata-kata yang dianggap tidak penting atau tidak bermakna yang sudah diinput ke dalam kamus stoplist dilakukan dengan fungsi 'data <- tm map (data, removeWords, cStopwordID)'. Untuk proses stemming dilakukan dengan menggunakan algoritma Pujangga dengan bantuan interface InaNLP (Indonesian Natural Language Processing).

Tabel 3. Contoh Hasil Proses Feature Selection

\begin{tabular}{cc}
\hline No. Tweets & Tweets Hasil Feature Selection \\
\hline 1 & lupa rawat kulit nutrisi penuhi \\
2 & penawaran menarik xiaomi \\
\hline
\end{tabular}

\section{c. Text Representation}

Pada proses ini, dilakukan perubahan data tweet menjadi matriks yang berisi frekuensi kemunculan kata (TF) pada sebuah dokumen, serta pembobotannya dengan menggunakan pembobotan TF-IDF. Document Term Matrix dengan pembobotan TF digunakan untuk mellihat kecenderungan term yang sering muncul pada 1303 tweets dari akun Twitter@LazadaID. Sedangkan Document Term Matrix dengan pembobotan TFIDF digunakan untuk melakukan clustering dengan algoritma Modified GustafsonKessel.

Berdasarkan hasil text representation, jumlah kata yang menyusun 1303 tweets dari akun Lazada Indonesia adalah 1364 kata. Seluruh kata tersebut akan menjadi variabel dari tiap tweet, dengan komponen dari matriks berupa jumlah dari suatu kata pada tiap 
tweet.Proses perubahan tersebut dilakukan dengan menggunakan fungsi 'as.matrix(weightTfIdf(m= DocumentTermMatrix(data), normalize = TRUE) )'.

Tabel 4. Hasil Document Term Matrix Pembobotan TF

\begin{tabular}{ccccccccc}
\hline No & Tweet & bayi & belanja & diskon & $\ldots$ & promo & unilever & voucher \\
\hline 95 & $\begin{array}{c}\text { maybelline diskon } \\
\text { voucher tambah belanja }\end{array}$ & 0 & 1 & 1 & $\ldots$ & 0 & 0 & 1 \\
717 & $\begin{array}{c}\text { unilever voucher diskon } \\
\text { langsung unilever diskon }\end{array}$ & 0 & 0 & 2 & $\ldots$ & 0 & 2 & 1 \\
\hline
\end{tabular}

Tabel 5. Hasil Document Term Matrix Pembobotan TF-IDF

\begin{tabular}{ccccccccc}
\hline No & Tweet & bayi & belanja & diskon & $\ldots$ & promo & unilever & voucher \\
\hline 95 & $\begin{array}{c}\text { maybelline diskon } \\
\text { voucher tambah belanja }\end{array}$ & 0 & 0,603 & 0,461 & $\ldots$ & 0 & 0 & 0,632 \\
717 & $\begin{array}{c}\text { unilever voucher diskon } \\
\text { langsung unilever diskon }\end{array}$ & 0 & 0 & 0,658 & $\ldots$ & 0 & 1,682 & 0,451 \\
\hline
\end{tabular}

\section{2. $\quad$ Algoritma Modified Gustafson-Kessel Clustering}

Proses clustering dengan algoritma Modified Gustafson-Kessel clustering dilakukan dengan menggunakan fungsi 'result $=\operatorname{MGK}(\mathrm{Z}, \mathrm{UO}, \mathrm{m}, \mathrm{tol}$, beta, gamma)' pada command window MatLab 2015a. Data yang digunakan adalah Document Term Matrix dengan pembobotan TF-IDF. Pangkat fuzzyfier yang digunakan adalah $m=3,75$, nilai tersebut merupakan hasil yang paling optimal dari proses trial and error karena menghasilkan fungsi keanggotaan $u_{i k} \neq 1 / c$. Untuk batas error terkecil dan nilai threshold yang digunakan sebesar $\varepsilon=10^{-3}$ dan $\beta=10^{15}$ [2]. Sedangkan nilai parameter pembobot yang digunakan sebesar $\gamma=0,3$. Proses clustering dilakukan sebanyak 5 kali dengan jumlah cluster yang berbeda-beda, dimulai dari jumlah cluster sebanyak 2 sampai dengan 6 cluster.

Jumlah cluster optimum dari proses clustering ditentukan menggunakan indeks validitas Partition Coefficient (PC) dan Classification Entropy (CE). Hasil yang didapat yaitu untuk jumlah cluster sebanyak 4, 5, dan 6 cluster, hanya 3 cluster dari total seluruh cluster yang memiliki anggota kelompok. Jadi, dapat disimpulkan bahwa tweets dari akun @LazadaID hanya dapat dikelompokkan dengan jumlah cluster maksimal sebanyak 3 cluster. Sehingga dalam penelitian ini akan dilakukan pengukuran validitas Partition Coefficient (PC) dan Classification Entropy (CE) terhadap pengelompokan dengan jumlah cluster 2 dan 3 saja.

Tabel 6. Nilai Partition Coefficient dan Classification Entropy

\begin{tabular}{ccc}
\hline $\begin{array}{c}\text { Jumlah } \\
\text { Cluster }\end{array}$ & $\begin{array}{c}\text { Partition } \\
\text { Coefficient }(\mathrm{PC})\end{array}$ & $\begin{array}{c}\text { Classification } \\
\text { Entropy (CE) }\end{array}$ \\
\hline 2 & 0,048744 & 1,098612 \\
3 & 0,148658 & 0,693143 \\
\hline
\end{tabular}

Berdasarkan Tabel 6 dapat dilihat bahwa jumlah cluster optimum diberikan untuk jumlah cluster sebanyak 3 cluster karena memiliki nilai Partition Coefficient (PC) yang paling besar dan nilai Classification Entropy (CE) paling kecil dibandingkan dengan nilai pada jumlah cluster sebesar 2. Jadi, jumlah cluster yang akan dianalisis pada penelitian ini adalah sebanyak 3 cluster. Hasil clustering dengan jumlah 3 cluster dapat dilihat pada Tabel 7.

Tabel 7. Hasil Clustering dengan Algoritma Gustafson-Kessel

\begin{tabular}{ccc}
\hline $\begin{array}{c}\text { Cluster } \\
\text { ke- }\end{array}$ & Nomor Anggota Tweet & Jumlah \\
& Anggota \\
\hline
\end{tabular}




\begin{tabular}{ccc}
\hline 1 & $19,135,137,183,191,201,206,234,269,408,462,487,515$, & 2 \\
& $777,969,988,1023,1178,1226,1242,1246,1252$ & \\
2 & $2,3,4,5,7,9,10,11,13,15,18,21,25,26,27,28,30,31,33$, & 787 \\
& $34,35,36,37,40,41,42,45, \ldots, 1226,1242,1246,1252$ & \\
3 & $1,6,8,12,14,16,17,20,22,23,24,29,32,38,39,43,44,47$, & 494 \\
\hline
\end{tabular}

Analisis lanjut untuk menginterpretasikan setiap cluster pada penelitian ini dibantu dengan wordcloud seperti pada Gambar 1. Wordcloud digunakan untuk melihat kata-kata yang menyusun masing-masing cluster. Dari wordcloud pada Gambar 1 terlihat bahwa pada cluster 1 kata "iphone" memiliki ukuran paling besar, sehingga dapat disimpulkan bahwa kata "iphone" memiliki frekuensi kemunculan paling tinggi. Setelah ditinjau kembali dengan mencari tweet yang berisi kata-kata berwarna kuning dan biru dapat disimpulkan bahwa tweet yang berada di dalam cluster 1 adalah tweet yang berisi penawaran barang-barang elektronik terbaru yang tersedia di Lazada seperti iphone, kabel, earphone, aukey, powerbank, charger, vivo, dan sebagainya.

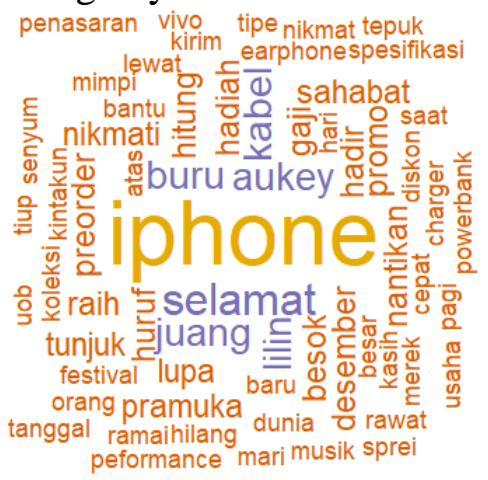

\section{Gambar 1. Wordcloud Cluster 1}

Dari wordcloud pada Gambar 2 terlihat bahwa pada cluster 2 kata yang paling banyak muncul adalah "diskon", "promo", "produk", "belanja”, dan "voucher". Kata yang berwarna biru merupakan kata dengan frekuensi kemunculan yang lebih rendah dibandingkan kata dengan warna lainnya. Setelah ditinjau kembali dengan mencari tweet dengan kata-kata yang sering muncul dapat disimpulkan bahwa tweet yang berada di dalam cluster 2 adalah tweet yang berisi penawaran mengenai diskon dan promo di Lazada. Kata diskon di dalam cluster 2 muncul sebanyak 220 kali dalam 202 tweets, sedangkan untuk kata promo muncul sebanyak 177 kali dalam 169 tweets. Untuk tweets yang berisi kata "belanja" hampir semuanya merujuk kepada ajakan untuk berbelanja di Lazada karena sedang diadakan banyak promo dan diskon.

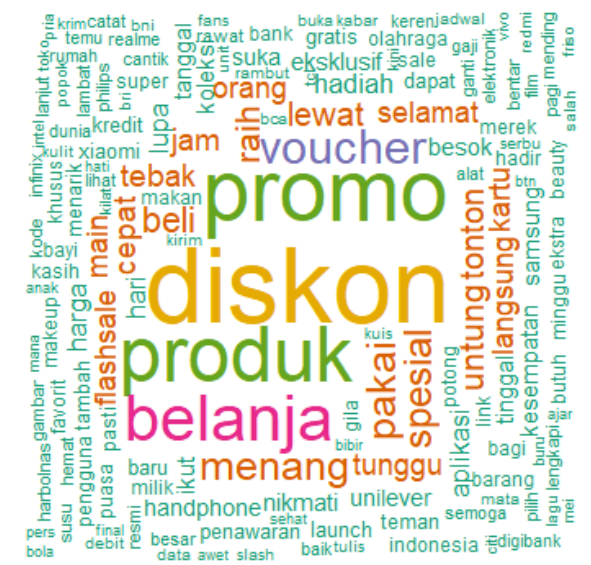

Gambar 2. Wordcloud Cluster 2 
Dari wordcloud pada Gambar 3 terlihat bahwa pada cluster 3 kata yang paling banyak muncul adalah "selamat", "menang", "voucher", "belanja", dan "hadiah". Kata yang berwarna biru merupakan kata dengan frekuensi kemunculan yang lebih rendah dibandingkan kata dengan warna lainnya. Setelah ditinjau kembali dengan mencari tweet dengan kata-kata yang sering muncul dapat disimpulkan bahwa tweet yang berada di dalam cluster 3 adalah tweet yang berisi tentang kuis berhadiah. Kata "selamat" di dalam cluster 3 muncul sebanyak 118 kali dalam 114 tweets, sedangkan untuk kata "menang" muncul sebanyak 110 kali dalam 109 tweets.

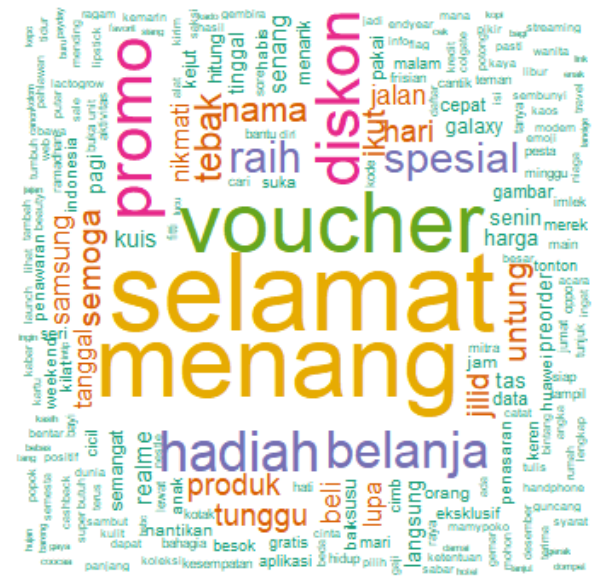

Gambar 3. Wordcloud Cluster 3

\subsection{Penentuan Konten yang Disukai Followers@LazadaID}

Konten yang disukai oleh para followers akun Twitter @LazadaID dapat ditentukan berdasarkan perhitungan rata-rata jumlah retweet dan like masing-masing cluster. Hal tersebut dikarenakan jika pengguna Twitter menyukai suatu tweet maka kemungkinan yang akan dilakukan pengguna tersebut adalah melakukan retweet atau menekan tombol like.

Tabel 8. . Hasil Perhitungan Rata-rata Jumlah Retweet dan Like

\begin{tabular}{cccccc}
\hline $\begin{array}{c}\text { Nomor } \\
\text { Cluster }\end{array}$ & $\begin{array}{c}\text { Jumlah } \\
\text { Tweet }\end{array}$ & $\begin{array}{c}\text { Jumlah } \\
\text { Retweet }\end{array}$ & $\begin{array}{c}\text { Jumlah } \\
\text { Like }\end{array}$ & $\begin{array}{c}\text { Rata-rata } \\
\text { Retweet }\end{array}$ & $\begin{array}{c}\text { Rata-rata } \\
\text { Like }\end{array}$ \\
\hline 1 & 22 & 570 & 566 & 25,90909 & 25,72727 \\
2 & 787 & 26387 & 20664 & 33,52859 & 26,25667 \\
3 & 494 & 21182 & 15664 & 42,87854 & 31,7085 \\
\hline
\end{tabular}

Pada Tabel 8 terlihat bahwa cluster yang memiliki rata-rata retweet dan like tertinggi adalah cluster 3 yaitu tweet mengenai kuis berhadiah, sedangkan jenis konten yang memiliki rata-rata retweet dan like terendah adalah cluster 1 yaitu tweet mengenai penawaran barangbarang elektronik. Berdasarkan hasil yang didapatkan terlihat bahwa konsumen dari perusahaan e-commerce Lazada Indonesia lebih tertarik terhadap program kuis berhadiah dibandingkan dengan diskon ataupun penawaran barang-barang elektronik. Oleh karena itu, PT Lazada Indonesia diharapkan mampu memanfaatkan konten kuis berhadiah sebagai sarana advertising pada platform Twitter semaksimal mungkin. Kuis berhadiah mampu memberikan dorongan kepada konsumen untuk melakukan pembelian dalam jumlah yang lebih banyak dan dapat meminimumkan perilaku berganti-ganti merek [4].

\section{KESIMPULAN}

Penerapan algoritma Gustafson-Kessel untuk clustering tweets pada akun Twitter @LazadaID menghasilkan 3 cluster tweet dengan konten mengenai penawaran barang elektronik, diskon dan promo, serta mengenai kuis berhadiah. Jumlah 3 cluster tweet yang dibentuk ditentukan berdasarkan nilai indeks validitas Partition Coefficient (PC) terbesar dan nilai Classification Entropy (CE) terkecil. Dari ketiga cluster tersebut didapatkan jenis 
konten dengan rata-rata jumlah retweet dan like tertinggi yaitu tweets mengenai kuis berhadiah, serta rata-rata terendah yaitu mengenai penawaran barang elektronik. Oleh karena itu, PT Lazada Indonesia dapat menggunakan tweets dengan konten kuis berhadiah sebagai sarana advertising pada platform media sosial Twitter karena tweet tersebut banyak disukai oleh para followers @LazadaID.

Ada beberapa perbaikan yang dapat dilakukan pada penelitian selanjutnya, yaitu menggunakan metode clustering yang lebih efisien serta memiliki kecocokan dengan bentuk data yang relatif homogen. Kemudian untuk menambah akurasi dari tahapan preprocessing data dapat digunakan composite tokenization dalam proses tokenizing.

\section{DAFTAR PUSTAKA}

[1] Aseanup, 2019. Top 10 E-commerce Sites in Indonesia 2019. https://aseanup.com/top-ecommerce-sites-indonesia/. Diakses 1 Maret 2019

[2] Babuska, R., Veen, P. v. d. \& Kaymak, U., 2002. Improved Covariance Estimation for Gustafson-Kessel Clustering. Netherlands: Delft University of Technology.

[3] Castella, Q. \& Sutton, C., 2014. Word Storms: Multiples of Word Clouds for Visual Comparison of Documents. Seoul, International Conference on World Wide Web, Vol. 1.

[4] F. Tjiptono, Brand Management \& Strategy. Yogyakarta: Andi Offset, 2005.

[5] Farag, S. \& Lyons, G. D., 2007. Conceptualising barriers to travel information use. United Kingdom, Proceedings of the 39th Annual Universities.

[6] Feldman, R. \& Sanger, J., 2007. The Text Mining Handbook. New York: Cambridge University Press.

[7] Gunelius, S., 2011. 30 Minute Social Media Marketing. United States: McGraw Hill.

[8] Gustafson, D. \& Kessel, W., 1979. Fuzzy Clustering with a Fuzzy Covariance Matrix. San Diego, Hal. 761-766.

[9] Jansen, S., 2007. Customer Segmentation and Costumer Profiling for a Mobile Telecommunications Company Based on Usage Behavior :A Vodafone Case Study. Maastricth: University of Maastricth.

[10] Kemenkominfo, 2019. Kominfo : Pengguna Internet di Indonesia 63 juta. https://www.kominfo.go.id/content/detail/3415/kominfo-pengguna-internet-di-indonesia-63juta-orang/0/berita_satker. Diakses 1 Maret 2019.

[11] Littlejohn, S. W. \& Foss, K. A., 2009. Teori Komunikasi. Jakarta: Salemba Humanika.

[12] Oglethorpe, J. E. \& Monroe, K. B., 2008. Determinants of Perceived Health and Safety Risks of Selected Hazardous Products and Activities. The Journal of Consumer Affair, Vol. 28(2), Hal. 326-346.

[13] Robertson, S., 2005. Understanding inverse document frequency: On theoretical arguments for IDF. Journal of Documentation, Hal. 502-520.

[14] Santosa, B., Conway, T. \& Trafalis, T., 2007. A Hybrid Knowledge Based Clustering Multiclass SVM Approach for Genes Expression Analysis.. Boston: Springer.

[15] Tala, F. Z., 2003. A Study of Stemming Effects on Information Retrieval in Bahasa Indonesia. Netherland: Institute for Logic, Language, and Computation Universiteit van Amsterdam. 